\title{
AAS education programs for photonics technicians
}

Leno Pedrotti, Chandrasekhar Roychoudhuri, Arthur Guenther

Leno S. Pedrotti, Chandrasekhar Roychoudhuri, Arthur H. Guenther, "AAS education programs for photonics technicians," Proc. SPIE 3831, Sixth International Conference on Education and Training in Optics and Photonics, (16 June 2000); doi: 10.1117/12.388723

Event: Education and Training in Optics and Photonics (ETOP'99), 1999, Cancun, Mexico 


\title{
AAS education programs for photonics technicians
}

\author{
Leno S. Pedrotti* a ${ }^{*}$ Chandra S. Roychoudhuri ${ }^{b}$, Arthur H. Guenther ${ }^{c}$ \\ ${ }^{a}$ Center for Occupational Research and Development, Waco, TX 76710 \\ ${ }^{\mathrm{b}}$ Photonics Research Center, University of Connecticut, Storrs, CT, 06269 \\ ${ }^{c}$ Center for High Technology Materials, University of New Mexico, Albuquerque, NM 87106
}

\begin{abstract}
Photonics is a critical enabling technology for the 21 st century and photonics technicians are an integral part of the supporting workforce. This paper outlines a two-year AAS education program designed to produce competent photonics technicians who can (1) enter the workforce directly upon graduation from the two-year program or (2) continue their education toward an appropriate four-year bachelor's degree program. As an appropriate foundation for the two-year AAS photonics program, consideration is given also to an optimal technology preparatory program for high school students who are moving towards careers in photonics.
\end{abstract}

Keywords: photonics, technician education, AAS programs, articulation

\section{INTRODUCTION}

Over the past 10 years, the dramatic growth of photonics as a key industry has caught the attention of this nation. In 1994, the President's Council on Competitiveness singled out photonics as a critical technology for the economy of the United States. ${ }^{1}$ In 1995, the Optoelectronic Industry Development Association (OIDA) predicted that the U.S. photonic industry would double in size every four years, growing to a $\$ 500$ billion dollar market by the year 2013 . $^{2}$ In 1998 , the Committee on Optical Science and Engineering, working under the auspices of the National Research Council, published a comprehensive assessment of the broad field of optical science and engineering entitled, "Harnessing Light," 3 establishing clearly the growing importance of optics and photonics for the 21 st century. With the established and acknowledged growth of such a dynamic industry, there exists, as always, a parallel need for a skilled workforce, a workforce able to sustain the growth and fuel the inevitable expansion. Today, all readable signs indicate that we are falling dangerously short of producing that needed workforce. In 1997, Photonics Spectra, a widely-read trade journal covering the world of optics and lasers, focused on the acute shortage of optical technicians, pointing out that the shortfall "has reached what experts say is a virtual crisis stage in this country." A year later, this same journal highlighted the growing shortage of photonics technicians, noting that "When you ask photonics companies about the most difficult jobs to fill, you hear in almost unanimous voice: 'Technicians'!"5 And in spring of 1999, based on a comprehensive market survey covering key states in the Northeast, the Northwest, Middle America, the Southwest, and along both the Atlantic and Pacific coasts, preliminary research results by Bolt Systems, Inc. are showing a shortfall of 1.5 million technicians for the U.S. photonics industry as a whole with at least 600,000 laser and optics technicians needed by the year $2006 .^{6}$

The message is clear, then, that the United States must alert its educational leaders and tap its educational resources to develop new comprehensive education programs for photonics technicians. The laser/electro-optic (LEOT) materials developed by the Center for Research and Development (CORD) ${ }^{7}$ in the late 1970 s for training laser technicians-and revised in part through the 1980s and early 1990s-are no longer adequate for the education of photonics technicians. A new set of learning materials are needed to merge optics with electronics, lasers, and fibers. And a new two-year curriculum is needed to build on stronger foundations in mathematics and science and develop technical programs which prepare photonics technicians with those head and hand skills identified by the photonics industry.

\footnotetext{
* Correspondence: E-mail: pedrotti@cord.org; Telephone: 254-772-8756; Fax: 254-772-8972
} 


\section{DEFINITIONS}

Before we examine in some detail the proposed AAS education programs for photonics technicians-the thrust of this paper-we feel it would be helpful to give our working definitions of photonics and technicians. In the context of this paper, then, we have adopted the following:

- Photonics: Laurin Publishing (Photonics Spectra publishers) defines photonics as "the generation, manipulation, transport, detection and use of light information and energy whose quantum unit is the photon." Others-including we here at CORD-define photonics somewhat similarly as "the generation, manipulation, transport, detection and use of light and other forms of radiant energy in diverse technologies."

- Technician: We define a technician as "one skilled in assembling, disassembling, troubleshooting, adapting, modifying and interfacing technological devices, equipment and systems." This definition helps us distinguish technicians from their traditional supervisors-engineers and scientists-who are generally involved more with the creation of theories and the design of new devices and systems than with the efficient assembly, modification, and use of devices and systems.

We have used these definitions of photonics and technician to help us sort out and identify the appropriate skills required by a photonics technician, and to steer us accurately in the development of effective two-year AAS photonics education programs. While we shall concentrate in this paper on the curricular contents of the two-year AAS program, we shall look also at the four years of education before the AAS program and the optional two years of education after the AAS program. We take a brief look at this " $4+2+2$ " plan of integration in the next section.

\section{A 4+2+2 EDUCATIONAL PLAN}

In an earlier paper $^{8}$ dealing with photonics education for technicians, engineers and scientists, a so-called $4+2+2$ plan of education was described, sequencing the separate-but integrated-contributions of four-year high schools, two-year community colleges, and four-year colleges. This overall plan-as given previously in that paper-is reproduced in Figure 1.

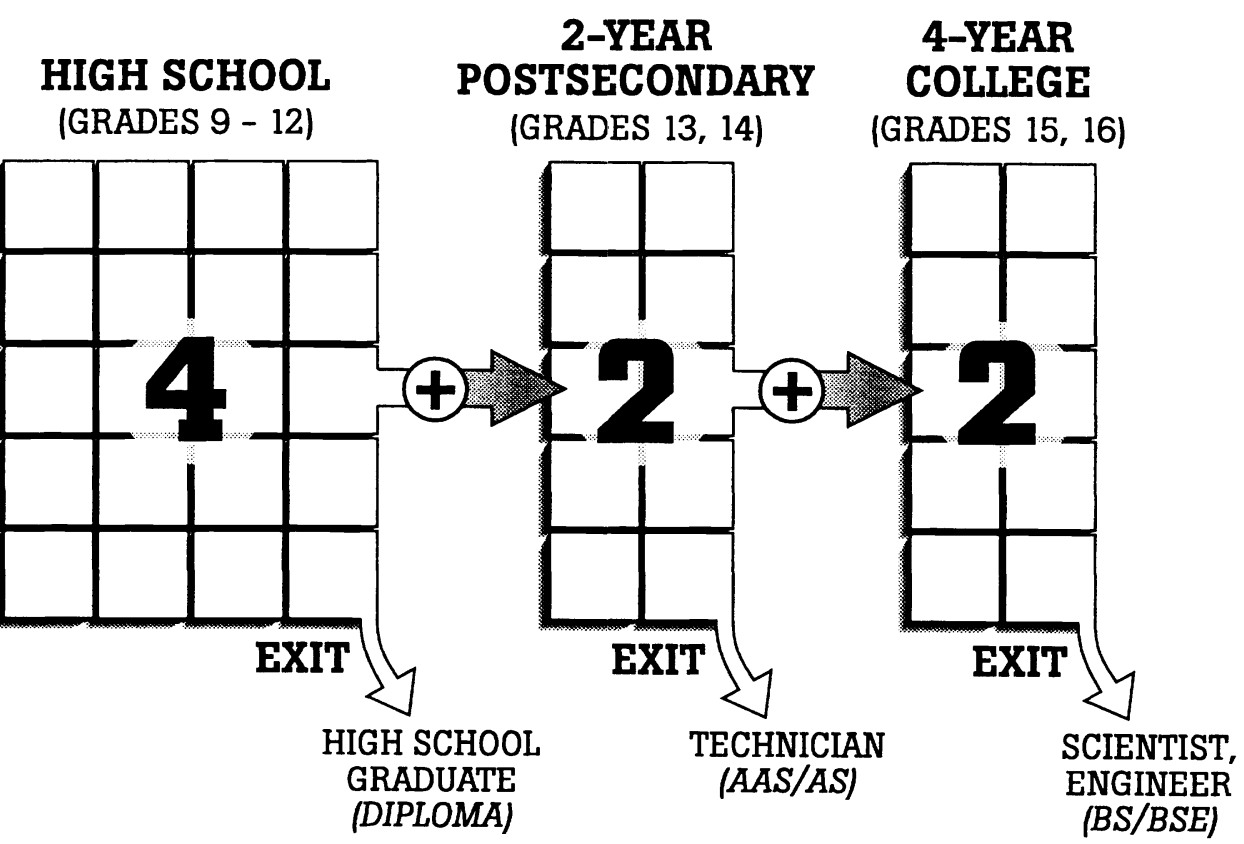

Figure 1 A 4+2+2 plan of education

While many students enter two-year colleges at different ages and with widely different backgrounds-and not necessarily directly out of high school-we feel it is helpful to describe an "ideal" high school foundation for those 
"technology" students in high school who are interested early-on in careers in optics and photonics and who plan to go on directly to two-year colleges for further study. We describe such a foundation in conjunction with the proposed two-year AAS program outlined below. Further, since reality has taught us that even the best-intentioned students sometimes go directly to work after completing high school-rather than on to a two-year college for the AAS degree-such a foundation of high school courses under their belt ought to ensure that they have-at the least-a minimum of entry-level skills for post high school employment.

Additionally, while our goal remains firmly to increase the production of photonics technicians for our country's workforce, we feel it is important to provide a clear road map for those AAS graduates who express a desire to go on for more education after the AAS - articulating upward toward a BS and beyond. We shall indicate later in this paper those transition courses and areas required to facilitate a career switch from an AAS program to a BS program.

\section{AAS PHOTONICS EDUCATION PROGRAM-WITH A HIGH SCHOOL FOUNDATION}

Figure 2 identifies the $4+2$ parts of the photonics technician education program, that is, the high school foundation plus the two-year college concentration. This figure identifies the courses and sequences for grades 9-14, involving the major "technical" areas of mathematics, science, and technology, and other "nontechnical" areas which include the social sciences, language, history, government, humanities and health. As mentioned above, the "technical" courses spelled out in the fouryear high school part represent an ideal foundation for a potential photonics technician. The authors are aware that the formation of high school programs, developed as special "feeders" for two-year AAS photonics programs, takes effort and planning, and does not happen overnight. ${ }^{*}$ Nevertheless, the merger of the two makes such good pedagogical sense that we continue to encourage strongly the integration of a high school feeder program with a two-year postsecondary program. At the very least, such a 4+2 plan identifies the mathematics, science and technology courses required at the four-year high school level for optimal entry into a two-year photonics AAS program. At its best, it guarantees an effective education of those skilled photonics technicians required by industry.

\subsection{The technology foundation in high school; grades 9-12}

In addition to the basic grounding in mathematics (algebra, geometry and precalculus) and science (biology, chemistry and physics) shown in Figure 2 for grades 9-12, an excellent foundation in technology would include one-year courses in:

- Computer applications

- Machining and materials processing

- DC/AC electricity

- Digital electronics

- Solid state devices

- Laser basics

The course on computer applications guarantees computer literacy with the likes of spreadsheets, bar graphs, Windows 95, E-mail, and Internet. The course on machining and materials processing, dealing with basic machine shop practice and device fabrication, is considered a very useful course for photonics technicians, developing those hand skills they will use throughout their careers. The heavy emphasis on electronics-covering DC/AC basics, digital theory and application, and solid state devices-is clearly warranted because of the importance of electronics and electronic devices in photonics. And the course on laser basics - taught at an introductory, orientation level-is essential to stimulate the interest of the "future photonics technicians." Each of the courses listed above has already been developed for use in traditional high schools and so are readily available for inclusion in high school programs.

\footnotetext{
* CORD has for the past decade encouraged the formation of "Tech Prep" programs. These programs combine four years of high school study with two years of community college study in a seamless $4+2$, six-year curricular program. Such Tech Prep programs exist currently across the nation-supporting careers in agriculture, business and office, health, home economics, and technology. The 4+2 plan suggested here-in support of photonics technician education-is part of the Tech Prep national movement.
} 


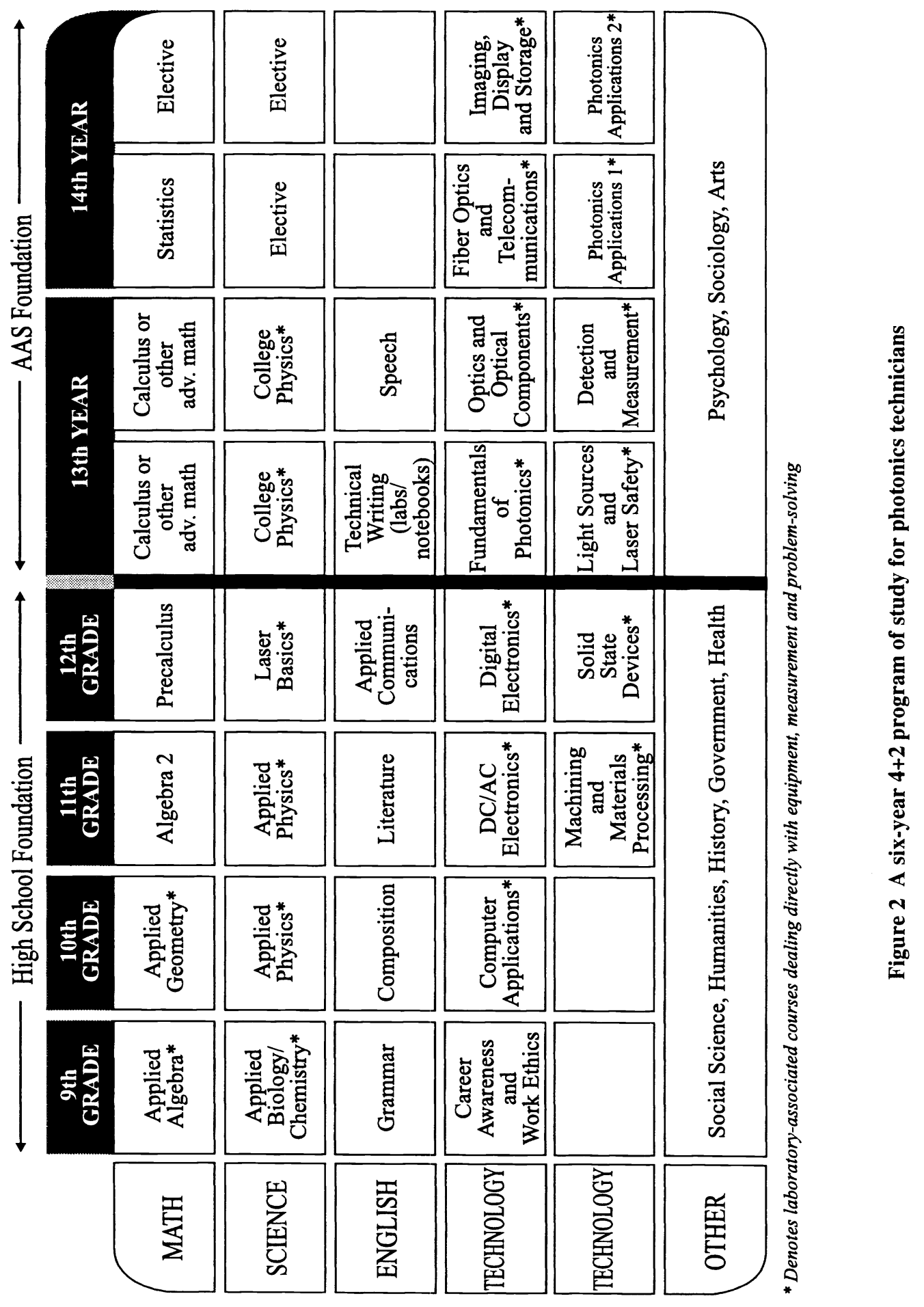


Two other course areas we feel keenly about are those entitled career awareness and work ethics. These are to be taken as early as possible in the high school program, as shown in Figure 2, to assist students with career choices in technology and to acquaint them with appropriate personal conduct on the job. The teaching of work ethics in high school classes, for example, has long received strong endorsement from industry.

Before leaving this section on the high school foundation, we wish to highlight the importance of the associated, indepth, hands-on laboratory experiences embedded in those courses marked with an asterisk in Figure 2. These courses include not only the traditional laboratory-based courses in electronics and machining, but in applied mathematics and applied physics courses as well. Since hand skills are a "trump suit" in the arsenal of technician skills, it is important to have these skills honed early in the technician's career.

\subsection{The photonics technology core in the AAS program}

The heart of the proposed AAS photonics technician program is detailed in the 13th and 14th year of the postsecondary school, as shown in Figure 2. Concentration in mathematics continues with one year of calculus and one-half year of statistics. One year of college-level physics-ideally calculus based-continues the concentration in the science area. The foundation of the AAS program for a photonics technician is contained within the core of eight technology courses.* The eight courses are each a semester in length and are spread out over the 13th and 14th year, as shown in Figure 2. These courses build on the technology foundation developed at the high school level and continue the intensive hands-on laboratory experience begun in the high school laboratories. Briefly, they are described as follows:

- Fundamental of Photonics - covers an overview of photonics including the nature and propagation of light, laser safety, basic optics, detectors and vision, waveguides and fibers, telecommunication, holography and imaging/display/storage

- Light Sources, Lasers and Laser Safety - covers the characteristics of nonlaser light sources, principles of laser operation, characteristics, operation and maintenance of current lasers, and the practice of laser safety in the laboratory

- Optics and Optical Components - covers the basics of geometrical and physical optics with attention to the use of mirrors, lenses, prisms, coatings, filters, gratings and polarizers in optical systems

- Detection and Measurement - deals with the complete array of electron and light/photon detectors and the art of inspection and measurement in the laboratory

- Fiber Optics and Telecommunications - covers the physics of fibers, the packaging of fiber optics systems from transmitter to receiver, and the state-of-the-art technology in telecommunications. (Reference 3 on "Harnessing Light" makes a compelling statement about the strong relationship between information technology and photonics!)

- Photonics Applications 1 - covers examples of the use of optical and photonic equipment in medicine, environmental control, industrial measurement and production, imaging and display, and scientific R\&D, through in-depth photonics laboratory experiences

- Imaging. Display and Storage - covers the science and technology of image formation, display and storage with high resolution and fidelity, dealing with related equipment such as CCD cameras, vidicons, image intensifiers, CRTs, light crystals, LCDs and LEDs

- Photonics Applications 2 - continues the in-depth laboratory experiences begun in Photonics Applications 1 with additional applications in material processing, national defense, optical data storage, graphic arts, bar code scanners, laser printers, etc.

Each of the eight courses listed above is generally made up of 8-10 modules-sort of like chapters in a textbook. Each module covers an essential part of the technical content of the designated course and contains specific laboratories and problem-solving exercises directly related to the central theme of the module. Developed in this modular, stand-alone fashion, the modules offer the flexibility of being able to be used sequentially - as designed for in each of the eight courses, or of being selected for separate study—as driven by special requirements.

\footnotetext{
* The initial project for the development of the eight courses is being funded by the National Science Foundation through a grant to the University of Connecticut. The principal investigator for the project, "Science and Technology Education in Photonics (STEP)" is Chandra S. Roychoudhuri, Photonics Research Center, University of Connecticut, Storrs, CT.
} 
It is important to emphasize again here - as it was with the laboratory-associated courses identified at the high school level-that each of the eight courses described above is heavily dependent on hands-on laboratory involvement. The modules in each course requires the student to spend considerable time in the laboratory-learning how to maintain, operate, calibrate and apply photonics equipment.

\subsection{Transferring to a four-year program}

As alluded to earlier, some students in a photonics education program may wish to transfer directly from a two-year college-with their AAS degree in hand-to a four-year college in pursuit of a Bachelor of Science. ${ }^{*}$ The most direct options generally open are:

- Transfer into a program leading to a BSET (Bachelor of Science in Engineering Technology)

- Transfer into a program leading to a BSEET (Bachelor of Science in Electronic Engineering Technology)

Either the BSET or BSEET is a viable transfer path since either one builds less on the abstraction in mathematics, science, and technology and more on the practical application of the technology. This latter mode of education fits quite naturally with the educational delivery and content found in the proposed AAS Photonics Technician education program.

For students transferring to either a BSET or BSEET program, the third and fourth years-placed on top of their two-year AAS program-are spent largely making up the math and science courses typically covered in the first two years of a four-year engineering technology program. These makeup courses may include additional mathematics courses (differential equations, for example) along with calculus-based science courses. Upper-level technical courses in the third and fourth year of the four-year college program are, of course, required. However, many of the technical courses taken at the two-year college may be accepted as viable substitutes for these upper-level courses.

Movement from a four-year high school into a two-year postsecondary school and on to the last two years of a fouryear college is described simply as a $4+2+2$ program. Depending on scheduling problems and the timely availability of required courses for the last two years at the four-year college, such a $4+2+2$ plan would take eight years, identical with the eight years required in a traditional $4+4$ plan pursued by students going directly from high school to a four-year college. As a minimum, those in a $4+2+2$ plan may have to spend an extra summer in pursuit of the BSET or BSEET degree, due to scheduling difficulties and/or special course requirements for the degree they are pursuing.

If the goal of the transfer student is to attain a bachelor of science in the traditional fields of electrical engineering, optical science or applied physics, most likely an additional year of work will be required, leading to nine years invested in a $4+2+1+2$ plan. The extra year comes about because those basic courses which are steeped more deeply in principle and theory - generally required as part of four-year programs in electrical engineering, optical science and applied physics-will generally not have been covered in the two-year AAS program, and must necessarily be taken before moving on to the third and fourth years in such traditional programs. The cost of the additional year for the completion of the BS in a $4+2+1+2$ program will have to be measured against the increased attractiveness of the graduate to the labor market-as a hybrid technician, engineer and scientist - and against the increased potential for earning higher salaries.

\section{MAINTAINING CURRENCY IN TECHNICIAN-EDUCATION PROGRAMS}

It is a formidable task to develop appropriate photonics-core learning materials for the education of photonics technicians. It is less formidable, perhaps, but still challenging to maintain currency once the materials have been developed. This is especially true in a field so rapidly developing and changing as photonics. To attempt to solve this dilemma-without resorting to major (costly) revisions every two years or so-CORD has been experimenting with a morphing process-under a grant from the Fund for the Improvement of Postsecondary Education (FIPSE) ${ }^{9}$ - wherein developed courses are entered intact on the world-wide web and made available to photonics course instructors in the field. Via communications systems arranged between CORD and the field, messages from instructors and industry reps-on content modification, content updates, improved laboratory exercises and successful teaching techniques-are sent to CORD. These messages are processed by a "web master" at CORD, and, after appropriate evaluation and modification, are posted on the specific course

\footnotetext{
* Considerable more details on course requirements for both transfer and makeup is found in the article listed under Reference 8.
} 
on the web-for sharing with all instructors who are using the materials. In this way, each course on the web undergoes "revision in real time" and provides instructors in the field with "currency of content" as well as with beneficial interaction with colleagues. As of this writing, the success of the morphing experiment seems to depend heavily on the willingness of busy instructors to invest time in such a feedback process. If the morphing process works as designed, we will have solved a major problem in maintaining the currency and relevancy of technical course materials.

\section{A FINAL THOUGHT}

Developing learning materials for technicians is quite different from developing learning materials for traditional college students. While both need to develop the head skills and hand skills necessary for mastery of the discipline under study, there is a danger that materials intended for technicians will be developed with the same level of abstraction and "distance from application" as is the material in those mathematics, science, and technology courses traditionally prepared for the four-year college students.

It has been our experience that those students in high school who go on to become our best technicians-and valuable they are-enjoy working with their hands to assemble, disassemble, troubleshoot, modify, adapt, and interface devices and equipment. Generally they tolerate higher levels of abstraction in courses only when a direct connection is made between those abstractions and the practical applications they enjoy working on in the laboratory.

At the risk of over-generalizing, we think of scientists and engineers mainly as puzzle solvers with most of the "puzzles" they solve taking shape in their heads. As a group they are content to deal with abstract theories and derivationsready to create new theories and set the stage for new breakthroughs-either on paper or in the laboratories. By contrast, technicians-who also enjoy solving puzzles—deal with "puzzles" made up of tangible objects, situated mostly in front of them-on a lab bench, say. As a group they enjoy using gifted hand skills to create a better product or a better measurement technique.

It is a challenge and an art to develop appropriate learning materials for each. If the level of sophistication and abstraction contained in the learning materials for technicians is too high, we risk losing the future technician's interest andat the same time-relegate the learning materials to the role of "reference texts" on a shelf. On the other hand, if the rigor and elegance is too low, we risk educating technicians with great hand skills and "suspect" head skills. For technicians, our challenge is to develop materials that strike the right balance between abstraction and concreteness, between elegant rigor and practical application. The payoff is great-commensurate with the challenge.

\section{REFERENCES}

1 “Optoelectronics and Photonics Technology in Massachusetts-An Assessment and Educational Analysis." Prepared by the Minuteman Regional Science and Technology Optoelectronics and Photonics Task Force, Lexington, Massachusetts, 1998.

2 “Optoelectronics Technology Roadmap: Conclusions and Recommendations," Optoelectronics Industry Development Association, 1995

3 "Harnessing Light-Optical Science and Engineering for the 21st Century," National Academy Press, Washington, D.C., 1998

${ }^{4}$ O’Brien, Terrence K., "U.S. Programs Seek to Fill Optics Technicians Void,” Photonics Spectra, A Laurin Publication, Volume 31, October 1997, pp 82-84

${ }^{5}$ Weiss, Stephanie A., "Help Wanted!," Photonics Spectra, A Laurin Publication, Volume 32, April 1998, pp 90-99

${ }^{6}$ Private correspondence with Sarah Diggs, Bolt Systems, Inc., San Jose, CA, July 1999.

${ }^{7} \mathrm{CORD}$ is a nonprofit, public service organization-located in Waco, Texas-which helps educators and industries across the country address the education, training and retraining needs of the workforce.

${ }^{8}$ Pedrotti, L. S., N. Massa, E. P. Soulsby, J. Enderle, and C. S. Roychoudhuri, "Comprehensive Approach to Photonics Education for Technicians, Engineers, and Scientists in 4+2+2 Programs." SPIE 1995 International Conference on Education in Optics, San Diego, CA.

9 “Curriculum Morphing Project”; FIPSE Grant P116B972017, 09/01/98-08/31/00; Darrell Hull, CORD, Project Officer, Waco, TX 